Anales de Literatura Hispanoamericana

ISSN-e: 1988-2351

\title{
Genialidad, marginalización y locura en El perseguidor, de Julio Cortázar
}

\author{
Álvaro Pina Arrabal ${ }^{1}$
}

Resumen. El presente artículo se centra en las nociones de genialidad, marginalización y locura en el caso concreto de El perseguidor (1959), relato del escritor argentino Julio Cortázar. En particular, se presta atención a la figura del protagonista, Johnny Carter, en relación con su contrapunto Bruno y con la sociedad moderna occidental a la que se adscribe. Partiendo de presupuestos de ontología social, se sostiene la tesis de que es la fricción entre la sociedad y el individuo la que induce a la consideración de este último como un mero demente. Asimismo, se plantea la marginalización como una forma de identidad personal y se trata de determinar el grado de genialidad artística -si alguno- que tiene el personaje conforme a lo narrado.

Palabras clave: descentralización; demencia; identidad; colectividad; patología.

\section{[en] Genius, Marginalization and Madness in El perseguidor, by Julio Cortázar}

\begin{abstract}
The current article is focused on the notions of genius, marginalization and insanity in the specific case of $E$ I perseguidor (1959), a story by the Argentine writer Julio Cortázar. Special attention is paid to the figure of the protagonist, Johnny Carter, in relation with his counterpoint Bruno and with the modern Western society to which he belongs. Taking social ontology presuppositions as a point of departure, we defend the thesis that it is the friction between society and the individual that prompts the consideration of the latter as a mere lunatic. Likewise, we propose marginalization as a way of personal identity and we try to ascertain the degree of artistic brilliance of the character -if any- according to the narration.
\end{abstract}

Keywords: decentralization; madness; identity; community; pathology.

Cómo citar: Pina Arrabal, A. (2021) Genialidad, marginalización y locura en El perseguidor, de Julio Cortázar, en Anales de Literatua Hispanoamericana 50, 393-398.

La locura ha sido objeto de consideración filosófica y artística desde tiempos inmemoriales. Aunque a menudo percibida como una mera falta de cordura, en algunos casos puede ser también señal -e incluso fuente- de un talento fuera de lo común. Ya en el Fedro, Platón (2019: 458) pone en boca de Sócrates las célebres palabras que siguen: "Porque si fuera algo tan simple afirmar que la demencia es un mal, tal afirmación estaría bien. Pero resulta que, a través de esa demencia, que por cierto es un don que los dioses otorgan, nos llegan grandes bienes". El razonamiento del filósofo griego se ampara en una cosmogonía mitológica y divina de la realidad, reemplazada hoy por la ciencia y el uso crítico de la razón, pero no por ello deja de dar cuenta de que, en ocasiones, la genialidad puede ir de la mano de la locura; Isaac Newton, Edgar Allan Poe, Vincent Van Gogh, Robert Schumann o Virginia Woolf son solo algunos de muchos posibles ejemplos. Como epitoma el célebre verso de John Dryden en Absalom y Achitophel (1681), "great wits are sure to madness near allied" (los grandes ingenios son sin duda aliados íntimos de la locura) (Pujante, 2010: 19). Acaso como corolario, la demencia conlleva con frecuencia falta de entendimiento, alienación social y autodestrucción, ya sea en la realidad o en las representaciones de los mundos ficcionales del arte. Del mismo modo en que no todos los genios están locos, tampoco todos los locos son genios (muchos no son más que un peligro para quienes hacen un uso compartido de la razón), pero la hibridación que a veces se da de ambos caracteres tiene implicaciones que merece la pena considerar.

\footnotetext{
${ }^{1}$ Universidad de Cádiz. España.

E-mail: alvaro.pina@uca.es
} 
Este trabajo se centra en la idea de locura, asociada a la genialidad y la marginalización, en el cuento El perseguidor $^{2}$, del escritor argentino Julio Cortázar (1914-1984). En particular, el personaje de Johnny Carter (reiteradamente señalado por la crítica como trasunto literario del músico de jazz Charlie Parker y, en cierta medida, del propio Cortázar) constituye un ejemplo de interés, aún no del todo explotado, para los estudios sobre la vesania en la literatura. No en vano, el autor dio forma al personaje tras leer sobre los problemas mentales y familiares de los que el músico adoleció en vida. Charlie Parker es, en palabras de Alicia Saliva (2004: 121), un "[1]oco, suicida, drogadicto y visionario, pero querible, admirable, con una vida mucho más deseable que la de los cuerdos que le rodean". Todo esto hace de él una figura idónea para representar, desde la literatura, la coexistencia de genialidad y locura en un mismo ser, así como las consecuencias que esta provoca tanto en él como en quienes lo rodean.

Si bien los rasgos de demencia atribuibles al personaje de Johnny Carter no tienen base en un diagnóstico clínico concreto, la presencia de médicos e incluso de enfermedades es permanente a lo largo de todo el relato; al fin y al cabo, se trata de un adicto al alcohol y la droga con tendencias catalogables como psicóticas desde una perspectiva social. Al comienzo del cuento, Dédée (la mujer que acompaña a Johnny y que trata de cuidarlo) sugiere llamar al doctor Bernard, al que él tacha de "triste idiota" (13) capaz tan solo de manifestar su gusto por el jazz. A mitad de la historia, Johnny incendia la habitación del hotel en el que se encontraba, teniendo que ser trasladado al hospital bajo vigilancia (46); allí, según cuenta Bruno (el narrador de la historia, un crítico de jazz de posición estable que representa el contrapunto de Johnny), lo ubican "en una sala donde hay otros dos enfermos" (47), lo que da cuenta de la convivencia frecuente del personaje con la enfermedad ajena y, en buena lógica, con la propia. Poco después, en una de las numerosas conversaciones entre Bruno y Johnny, este último se refiere a los médicos como "un mono con plumero" (48). Únicamente hacia el doctor Christie, que lo atendió cuando lo apresaron en Los Ángeles por provocar un escándalo en un bar, profesa Johnny algunas palabras laudatorias: "Un tipo estupendo, y eso que yo a los médicos..." (52). Se dan, en fin, evidencias suficientes a lo largo de todo el relato como para calificar a Johnny Carter de patológico, aunque esta condición -como se desarrollará más abajo- no es tan solo intrínseca sino también y principalmente- circunstancial.

Lejos de ser un mero enfermo sin capacidad operatoria, Carter es un artista de extraordinario talento, capaz de improvisar y de tocar música que el resto percibe como obras maestras (y el reconocimiento ajeno es un requisito indispensable para la configuración del genio). Es el caso de Amorous, el tema que Johnny eleva a "armonía celestial" (45) -en palabras de Bruno- durante una grabación hasta que él mismo la sabotea con un soplido repentino y con sus posteriores intentos de destruir la cinta. Los fogonazos de excelsitud de Johnny, que bien valen "uno de los momentos más grandes del jazz" (58) aun cuando él no es consciente, se encuadran, en realidad, en la angustia metafísica que siente y en su búsqueda constante de un orden distinto del real: la genialidad es, en Carter, un hipónimo de la locura. El artista plástico argentino Julio Lavallén (2016), que pasó tardes enteras en la casa de Jorge Luis Borges, asevera que "los artistas somos solo hacedores que gozamos de momentos de lucidez". Johnny Carter, como su correlato Charlie Parker, vive de esos chispazos de genialidad que afloran en medio de sus diversas angustias y adicciones.

No es por tanto de extrañar que, aun siendo El perseguidor una historia más sobre el Johnny Carter entre bastidores que sobre su producción musical en sí (Gyurko, 1980: 205), Bruno se centre solo en esto último en la biografía ficticia que publica sobre él: "Por discreción, por bondad, no he querido mostrar al desnudo su incurable esquizofrenia, el sórdido trasfondo de la droga, la promiscuidad de esa vida lamentable. Me he impuesto mostrar las líneas esenciales, poniendo el acento en lo que realmente cuenta, el arte incomparable de Johnny. ¿Qué más podía decir?” (79). Harina de otro costal es la importancia que su carácter impredecible tiene en su desempeño musical, pues el Carter persona y el Carter músico son -utilizando la noción de teoría de la literatura que Jesús G. Maestro (2014) toma del filósofo Gustavo Bueno- el mismo "sujeto operatorio" y no es materialmente posible disociar el uno del otro. Sin ir más lejos, Cortázar parece dotar de consciencia de ello al propio Johnny, que en una de las últimas conversaciones afirma: "Bruno, el jazz no es solamente música, yo no soy solamente Johnny Carter" (82). La cita encierra la relevancia que las precitadas adicciones e inquietudes metafísicas del personaje tienen en su faceta creadora. A partir de ellas, puede entenderse su situación como sujeto en cuanto que parte de un contexto social.

\footnotetext{
${ }^{2}$ Se utiliza la edición de 2009 de la editorial Gráficas'94, con ilustraciones de José Muñoz. Cuando se cita la obra a lo largo del trabajo (bien de manera directa entre comillas, bien mediante paráfrasis o alusión a momentos concretos), se incluye entre paréntesis tan solo el número de página a fin de evitar la redundancia con el año de publicación.
} 
La principal de las turbaciones que hacen de Johnny un loco a ojos de la sociedad -que no tanto un loco per se, como se argumentará- es sin duda su obsesión por el tiempo. Bruno da cuenta de ella desde el principio del relato: "He visto pocos hombres tan preocupados por todo lo que se refiere al tiempo. Es una manía, la peor de sus manías, que son tantas. Pero él la despliega y la explica con una gracia que pocos pueden resistir" (11). La categorización de esta inquietud como una simple "manía" implica ya el encasillamiento de Johnny como un loco cuyas ideas, fundadas en lo intuitivo, no obedecen al orden de lo racional. Tal es la dicotomía que plantea Cortázar en el cuento: lo empírico y racional, encarnado por Bruno, frente a lo poético e intuitivo, representado por Johnny (Jiménez, 1990: 49-50). Sin embargo, como explica el primero en la cita de arriba, la visión de su contrapunto es perfectamente verosímil, hasta el punto de generar atracción en los demás.

No por casualidad, más adelante Bruno termina por reconocer -en sus pensamientos internos- que tras la aparente locura de Johnny se oculta una realidad ulterior a la que solo lo sensible (el jazz, en este caso) permite llegar: "Johnny tiene razón, la realidad no puede ser esto, no es posible que ser crítico de jazz sea la realidad, porque entonces hay alguien que nos está tomando el pelo. Pero al mismo tiempo a Johnny no se le puede seguir así la corriente porque vamos a acabar todos locos" (54). El miedo que Bruno manifiesta aquí a incurrir en la paranoia de Carter supone, en realidad, el fracaso de la razón para asir esa otra realidad que el músico percibe $-\mathrm{y}$ que quizás penetra por momentos- durante el deliquio artístico. La mera idea de locura genera miedo; basten los versos del mexicano Xavier Villaurrutia (1966: 68), en su poema "Nostalgia de la muerte", para sintetizarlo: "existe un miedo, miedo mayor / mayor aún que el miedo a la muerte, / un miedo más miedo aún: el miedo a la locura". Terror e insania, como Villaurrutia expresa aquí mediante la reiteración continua de la palabra miedo, están íntimamente relacionados y se retroalimentan el uno al otro. Es más, este sentimiento de temor planea no solo sobre el individuo en sí, sino también, tal y como revela Bruno, sobre quienes forman parte de su entorno. Es aquí donde cabe introducir la idea de locura y, por extensión, de patología como una ontología de dimensión social.

Johnny naufraga al no encajar en un sistema heredero de la Ilustración, en el que priman la lógica y el signo matemático (Gambarotta, 2009: 2). El colectivo -esa inevitable abstracción- no acepta sus inestabilidades y tribulaciones suprasensibles, que no pasan el filtro implacable de la razón, y se le tacha de loco. No obstante, es exactamente ahí donde radica su identidad como individuo, pues se encuentra en una posición marginal a la par que permanece en sociedad: toca música con el grupo, tiene relación con varias personas (como Bruno o la marquesa) y es internado en el hospital (centro de indiscutible índole social). Evidentemente, ninguna de estas situaciones se da como los códigos de la comunidad promueven (si tiene contacto con la marquesa es para saciar sus adicciones -sexo, droga-y si está en el hospital es porque ha tenido un comportamiento contrario a las normas establecidas), pero no dejan de ser indicadoras de su presencia en la colectividad.

En rigor, Carter es un ser anómico, alguien que internamente carece de leyes pero que al mismo tiempo convive con las del sistema al que se adscribe. Es esta tensión la que lo configura como individuo y la que, a la postre, lo conduce a la muerte. Se trata de alguien descentralizado que, empero, habita en el centro; de alguien cuya seña de identidad es precisamente la alienación dentro de la sociedad. Como el Bartleby de Melville, Johnny permanece en el sistema para transgredirlo, vulnerando a los demás $-\mathrm{y}$ vulnerándose a sí mismo- como modus vivendi. Si la sociedad es un inmenso océano, Johnny es el elemento que, por su diferente densidad, va flotando y hundiéndose en función de su comportamiento en cada momento: tiene el extraordinario talento para destacar como músico de jazz, pero también una adicción evidente al alcohol y la droga. Ahora bien, ¿basta esto último para certificar su condición patológica, su locura? ¿O es la sociedad misma la que pone la etiqueta?

La noción de ontología social (Epstein, 2018), entendida aquí como la relación entre la naturaleza del individuo y la esfera social a la que pertenece, permite esclarecer la idea de locura en el caso de Johnny Carter. Como ya se ha subrayado, no resulta del todo posible fijar su presunta demencia en términos clínicos, pues, visto en asepsia, el consumo de alcohol y droga no deja de ser una mera alteración del metabolismo, e incluso un acto como quemar la habitación del hotel no es sino un simple cambio de estado de los materiales de la realidad. Como ocurre con la literatura misma, que tiene que ser validada a través de la interpretación de lectores e intérpretes y no solo existir como obra construida por un autor (véase la noción de Ontología de la Literatura de Jesús G. Maestro [2014]), el loco, para ser loco, ha de ser concebido como tal por la sociedad de la que forma parte. Si Johnny Carter fuera el único ser humano sobre la Tierra, ¿cabría hablar de él como un demente por mucha droga o alcohol que consumiera y por mucho desorden físico que causara en el mundo? El escenario puede parecer absurdo en cuanto que hipotético y virtualmente imposible, pero no deja de ser indicativo del papel crucial que juega la sociedad en la configuración de una patología como la locura; si la mayoría de individuos fuesen como Johnny Carter, ¿no sería acaso el loco aquel que no consumiera alcohol ni drogas? Después de todo, la medicina es una codificación humana de los estados que 
sobrevienen al ser y que atentan, en mayor o menor medida, contra su supervivencia como organismo unitario, pero la muerte, en puridad, no entraña más que un cambio en las agrupaciones de los átomos; en otras palabras, son los congéneres -la comunidad- quienes, por consenso social, ponen nombre al estado del ser. Esto puede antojarse irrelevante en el caso de una enfermedad plenamente objetivable como un cáncer de hígado, pero en el caso de la denominada locura los límites se tornan más difusos. Con la posmodernidad se han hiperrelativizado verdades que son absolutas y que no admiten discusión, y que por lo tanto deben ser restituidas con el tiempo, pero también se han puesto en tela de juicio otras que, como la locura, ciertamente encuentran su razón de ser en las atribuciones subjetivas de una ontología social relacional, inevitablemente abierta y cambiante.

Johnny Carter es, así, un engranaje que chirría por la fricción con los demás, no por sí mismo. Es el contraste entre la sociedad y él lo que realmente lo delimita como individuo; es, por paradójico que pueda parecer, la diferencia respecto de la sociedad lo que lo define e integra, pues sin ella no sería quien es. Esto se sugiere en el relato mediante dos códigos distintos: la intuición de Johnny y la racionalidad de Bruno, ambas conducentes a una misma realidad. Así, el primero afirma: "La música me sacaba del tiempo, aunque no es más que una manera de decirlo. Si quieres saber lo que realmente siento, yo creo que la música me metía en el tiempo" (17). Sin dejar de lado su obsesión por el tiempo, a través del cual busca entender y entenderse a sí mismo, Johnny intuye que su posición como músico es el resorte para calmar su desasosiego metafísico. Bruno, por su parte, justifica el comportamiento de Johnny desde un punto de vista mucho más lógico y racional: "Ni Marcel ni Art se han dado cuenta ayer de que Johnny no estaba loco cuando se sacó los zapatos en la sala de grabación. Johnny necesitaba en ese instante tocar el suelo con su piel, atarse a la tierra de la que su música era una confirmación y no una fuga" (40). Estas últimas palabras de Bruno condensan la esencia de Johnny como alguien que no vive fuera de la sociedad, sino en una posición marginal dentro de ella.

Esta circunstancia no ha pasado desapercibida para la crítica. Por un lado, Blanes (2011: 85-86) ha visto en la actitud de Carter la irrupción de una "nueva subjetividad", en la que el sujeto de la sociedad de consumo (que, siguiendo a Marcuse [1993: 41], asume como propias las necesidades de la colectividad) busca emanciparse de la amalgama grupal en pos de la identidad personal. Por otro lado, Suárez-Galbán (1998: 50-51) propone una doble lectura complementaria del relato a partir de la concepción de Johnny como negro en el centro de la Europa cultural (París): el texto como "alegoría" de la posición marginal del artista y como "crítica" del statu quo del momento, en el que el estilo alternativo del personaje choca con el racionalismo imperante. De este modo, el autor afirma que "cuando el gran músico pierde reiteradamente su saxofón, se desnuda frente a los demás, prende fuego a su habitación en un hotel, no se trata, desde luego, de actos estrambóticos, del epater de los decadente [sic], sin más, sino, como reconoce el propio Bruno, Johnny el artista, Johnny el negro, está pidiendo un simple reconocimiento como ser humano" (Suárez-Galbán, 1998: 51). Por sugerente que pueda resultar la idea de un Johnny completamente ajeno a la sociedad, lo cierto es que se trata de alguien que está buscando su sitio desde su propia forma de ser y sin renunciar a sus valores. Esta búsqueda, como tantas veces se ha señalado y como el propio Bruno certifica en uno de los pasajes más citados del cuento (58), hace de Johnny Carter un perseguidor y no un perseguido. El símbolo más elocuente a este respecto es probablemente el de las urnas llenas de cenizas en las que el personaje piensa de modo recurrente: a pesar de pasearse -imaginariamente- por innumerables campos de urnas, ninguna de ellas contiene nunca sus cenizas. Poco después de tener una de estas ensoñaciones, como le explica el propio Johnny a Bruno (47-48), empezaron a grabar Amorous.

Resulta llamativo que la crítica apenas haya reparado en este punto en la concomitancia con la "Ode on a Grecian Urn", de John Keats (2009: 20), y, en particular, con los últimos versos de la primera estrofa: "What mad pursuit? What struggle to escape? / What pipes and timbrels? What wild ecstasy?". Es bien sabido que Cortázar tradujo la obra de Keats al español (aunque, como ha señalado Mesa Gancedo [2012], muchas de estas traducciones han sido distorsionadas por editores modernos) y que incluso escribió Imagen de John Keats (publicado en 1996 pero compuesto entre 1951 y 1952), un libro fresco y heterogéneo en el que el autor argentino dialoga con el poeta inglés a través de numerosas fuentes textuales y experiencias. Siendo así, no sería de extrañar que, al escribir El perseguidor, Cortázar hubiera tenido en mente los precitados versos de Keats, que bien podrían sintetizar la idea general del cuento en la medida en que remiten a una "loca persecución", a un afán de emancipación ("What struggle to escape?"), a dos instrumentos musicales ("pipes and timbrels") y a un postrer "éxtasis salvaje", entendible también como "loco". En conjunto, toda la oda es una exploración de la belleza artística como medio de trascender el tiempo y la realidad, tal y como parece tratar de expresar Johnny Carter. En lugar de incluir una cita del poema de Keats al comienzo del relato, Cortázar optó por una del Apocalipsis ("Sé fiel hasta la muerte") y otra de Dylan Thomas ("O make me a mask"). Estas referencias, como sí se ha apuntado en un mayor número de ocasiones, sugieren la 
muerte del protagonista al ser fiel a sí mismo, al no ponerse la máscara del teatro del mundo y darse por ende de bruces contra la realidad.

Queda por abordar la cuestión de la -posible- genialidad en Johnny. Si, como se ha planteado en este artículo, la locura queda neutralizada en cuanto que adjudicación extrínseca de la sociedad al ser, cabe argüir que también la genialidad artística enraíza inevitablemente en la figura del crítico. No en vano, Jesús G. Maestro (2018) propone un esquema, con un eje de ordenadas y otro de abscisas, para medir el grado de genialidad de una obra. Su diagrama toma como referencia cuatro parámetros: la inserción o no de ideas nuevas y la utilización o no de técnicas nuevas. De este modo, se obtiene uno de entre cuatro posibles resultados: ideas y técnicas conocidas (kitsch); ideas conocidas pero técnicas nuevas (recurrencia); ideas nuevas pero técnicas conocidas (recursividad); e ideas y técnicas nuevas (la genialidad en su grado máximo). Asimismo, Maestro razona que la genialidad no puede fundamentarse en una reacción emocional, sino que ha de venir amparada por un reconocimiento externo del receptor (lector, en el caso de la literatura) y del intérprete. En el caso de El perseguidor, la persona con la capacidad crítica para realizar esta atribución no es otra que Bruno, pues, en palabras de Gambarotta (2009: 5), "es él el que desarrolla un esfuerzo teórico (estético) en torno a esas prácticas que encierran un sentido que puede, inclusive, escapársele a su propio productor". Este es el razonamiento que hace el personaje sobre la genialidad de Johnny durante una extensa reflexión:

Cualquiera puede ser como Johnny, siempre que acepte ser un pobre diablo enfermo y vicioso y sin voluntad y lleno de poesía y de talento. Aparentemente. Yo que me he pasado la vida admirando a los genios, a los Picasso, a los Einstein, a toda la santa lista que cualquiera puede fabricar en un minuto (y Gandhi, y Chaplin, y Stravinsky), estoy dispuesto como cualquiera a admitir que esos fenómenos andan por las nubes, y que con ellos no hay que extrañarse de nada. Son diferentes, no hay vuelta que darle. En cambio la diferencia de Johnny es secreta, irritante por lo misteriosa, porque no tiene ninguna explicación. Johnny no es un genio, no ha descubierto nada, hace jazz como varios miles de negros y de blancos, y aunque lo hace mejor que todos ellos, hay que reconocer que eso depende un poco de los gustos del público, de las modas, del tiempo, en suma. (54-55)

El juicio de Bruno como crítico es inequívoco: "Johnny no es un genio" porque no hace nada que el resto de músicos de jazz no haga. En todo caso "lo hace mejor que todos ellos", pero no utiliza ni técnicas ni ideas nuevas; en otras palabras, su producción no deja de ser un kitsch, siguiendo los presupuestos de González Maestro. Bruno, no obstante, deja la puerta entreabierta al afirmar al final que el reconocimiento como genio "depende un poco de los gustos del público, de las modas, del tiempo". Es aquí donde cobra relevancia otra de las indicaciones de Maestro en su teoría: el genio rara vez es reconocido entre sus contemporáneos porque, al hacer uso de un racionalismo inédito, rompe con el modelo vigente. Solo cuando las consecuencias de su innovación han sido neutralizadas es el genio reconocido como tal. Jesús G. Maestro ejemplifica este hecho con autores españoles como Góngora o Cervantes, que tardaron -especialmente el primero- bastante tiempo en ser encumbrados como genios de la literatura.

La pregunta ahora es evidente: ¿es Johnny Carter realmente un genio al que sus contemporáneos no saben reconocer? ¿O incluso su celebrado Amorous no es más que un pastiche compuesto con técnicas y/o ideas preexistentes? La duda, como refleja el pasaje de Bruno citado arriba, queda deliberadamente abierta por parte de Cortázar, y en cualquier caso no dejaría de ser una genialidad ficcional que forma parte del mundo literario del cuento. La única referencia al origen de la composición está puesta en boca de Bruno y resulta bastante vaga: "[...] Amorous. Ya sabes, ese tema de Alamo" (45) (existen, además, otras ediciones distintas de la aquí citada en las que aparece escrito "El Álamo" o "Álamo"). No obstante, incluso si Johnny no mereciera el calificativo de genio, el hecho de que, como admite Bruno, toque mejor que cualquier otro músico suscita una segunda pregunta, acaso más significativa: ¿favorece la presunta demencia de Johnny su talento artístico?

Se cita con frecuencia una frase, de fuente difícilmente identificable, del escritor Jiddu Krishnamurti en la que este sostiene que "estar bien adaptado a una sociedad profundamente enferma no es signo de buena salud". La supuesta locura de Johnny Carter está, como se ha propuesto en este trabajo, íntimamente relacionada con su inadaptación a la sociedad. Esta circunstancia potencia los sentimientos de solipsismo y angst que, en última instancia, conducen al personaje a la música, en la que parece encontrar solaz y arraigo mientras toca con un desempeño particularmente notable (cuando no propio de un genio). Incluso si no hay una relación de causa-consecuencia directa entre la marginalidad, la locura y la posible genialidad de Johnny, no cabe duda de que entre ellas se da un efecto de retroalimentación que descentraliza al personaje al tiempo que modela su idiosincrasia. De este modo, El perseguidor constituye un ejemplo representativo de cómo el 
individuo occidental, si no controla sus adicciones y comparte los códigos racionales de la sociedad moderna, deviene peligroso para los demás y, a la postre, para sí mismo.

\section{Referencias bibliográficas}

Blanes, Jaume P. (2011), "El perseguidor, de Cortázar, entre la figuración de la vanguardia y la emergencia de una nueva subjetividad", Revista De Crítica Literaria Latinoamericana, 37(74), págs. 71-92. Disponible en: www.jstor.org/stable/41940838

Cortázar, Julio (2009). El perseguidor. Barcelona: Gráficas'94.

Epstein, Brian (2018), "Social Ontology", en Edward N. Zalta(ed.). The Stanford Encyclopedia of Philosophy. Disponible en: https://plato.stanford.edu/archives/sum2018/entries/social-ontology/

Gambarotta, Emiliano M. (2009), "El crítico y el perseguidor. Sobre las potencialidades de la crítica a partir de un cuento de Julio Cortázar", Question, 1(24), págs. 1-11. Disponible en: https://perio.unlp.edu.ar/ojs/index.php/question/article/view/849

Gyurko, Lanin A. (1980). “Artist and Critic in Cortazar's 'El Perseguidor': Antagonists or Doubles?”, en Iberoamerikanisches Archiv, vol. 6, 3 (pp. 205-238).

Jiménez, Antonio (1990), “El sensualismo y 'la otra realidad' en ‘El perseguidor’ de Cortázar”, Mester, 19(1), págs. 4954. Disponible en: https://escholarship.org/content/qt2p77c32f/qt2p77c32f.pdf

Keats, John (2009). Les Odes. París: Arfuyen.

Lavallén, Julio (2016), Entrevista con Julio Lavallén por Fernando Abad, El Tribuno. Disponible en: https://www.eltribuno.com/salta/nota/2016-5-20-19-7-0--los-artistas-somos-solo-hacedores-que-gozamos-de$\underline{\text { momentos-de-lucidez }}$

Lawson, Anthony (2003). Reorienting Economics. Londres y Nueva York: Routledge.

Maestro, Jesús G. (2014). Contra las Musas de la Ira. El Materialismo Filosófico como Teoría de la Literatura. Asturias: Pentalfa Ediciones.

-------, ------- (2018). Teoría del Genio: explicación y justificación de la genialidad en el arte y la literatura. Vídeo disponible en: https://www.youtube.com/watch? $\mathrm{v}=\mathrm{Qd1}$ sQNBmM4k

Marcuse, Herbert (1993). El hombre unidimensional. Ensayo sobre la ideología de la sociedad industrial avanzada. Barcelona: Planeta-De Agostini.

Mesa, Daniel (2012), "Las verdaderas traducciones cortazarianas de John Keats", en Francisco Lafarga y Luis Pegenaute (eds.). Aspectos de la historia de la traducción en Hispanoamérica: autores, traducciones y traductores. Vigo: Academia del Hispanismo, págs. 231-239.

Platón (2019). Diálogos III. Barcelona: Gredos.

Pujante, David (2010), "Genio y carácter melancólico. El problema XXX del Pseudo-Aristóteles", Paraíso. Revista de poesía, 6, págs. 19-26. Disponible en: https://www.dipujaen.es/export/descargas/cultura/revista-paraiso/paraiso_6.pdf

Saliva, Alicia (2004), "Cortázar, el perseguidor", Cuadernos literarios, págs. 121-128. Disponible en: https://cuadernos.ucss.edu.pe/index.php/cl/article/view/206/198

Suárez-Galbán, Eugenio (1998), “Cortázar como negro: 'El Perseguidor”, en Coloquio Internacional Lo lúdico y lo fantástico en la obra de Cortázar. Madrid: Centre de recherches Latino-Americaines Université de Poitiers/Fundamentos, págs. 49-58.

Villaurrutia, Xavier (1966), "Nostalgia a la muerte”, en Obras. México: Fondo de Cultura Económica, págs. 68-69. 